\title{
PAGES restructured
}

The Earth System Science landscape is being shaken thoroughly these days; the associated changes bear risks as well as opportunities. Accordingly, the coming one to two years will be a time of transition in PAGES' internal organization and external relationships. The overview below outlines the developments in the global change program framework, the plans for PAGES, and a call for new working groups.

\section{Evolving program setting}

At the macro level, Future Earth, the new platform for global sustainability research, is getting ready to assimilate PAGES' parent organization, the International Geosphere-Biosphere Program (IGBP), by the end of 2015, in addition to two other Global Environmental Change programs, DIVERSITAS, and the International Human Dimensions Programme. The World Climate Research Program (WCRP) will also become an affiliate.

These structural changes serve expanding scientific ambitions: to provide "the knowledge and support to accelerate our transformations to a sustainable world" by integrating research better across disciplines, involving natural and social scientists, and engaging users of scientific information (a.k.a. stakeholders) in developing scientific questions and output strategies.

Over the last half year, Future Earth has become functional by establishing management structures and its first scientific activities. The recently launched website, futureearth.info, and the blog are worth a visit.

Twenty-seven Global Environmental Change projects, PAGES being one of them, have been invited to join the Future Earth network, and PAGES' Scientific Steering Committee (SSC) has indeed decided to request official membership over the coming months. At the same time, it was decided to strengthen collaborative ties with WCRP to ensure that the traditionally strong paleoclimate research in PAGES has a productive platform.

In the recently submitted funding proposals to the US and Swiss National Science Foundations, PAGES proposed a revised, streamlined science structure. It responds to the changing landscape of science programs and encourages integrative activities related to the sustainability issues prioritized by Future Earth and WCRP.

\section{Science structure changes}

The new PAGES science structure was inspired by community feedback solicited at the PAGES Open Science Meeting in 2013 in Goa and by discussions within the frameworks of IGBP, Future Earth and WCRP. The revised scheme reflects the key components of the Earth system: climate, environment, and humans (Fig 1). These three themes define the range of PAGES' scientific scope. Dissolving the boundaries between them may better reflect the increasingly integrative nature of PAGES' science than the current siloed foci structure. The Climate theme represents quantitative climate system dynamics from a paleo-perspective. The Environment theme deals with biogeosphere and ecosystem dynamics that interact with climate and introduce long-term feedbacks into the Earth system. The Humans theme covers long term environmental changes where humans are a major agent and where environmental changes have a demonstrable effect on the functioning of both ecosystem services and societies.

A new format, cross-topical integrated activities, has been introduced to facilitate scientific exchange, synthesis, and outreach across the existing working groups and the Future Earth and WCRP networks. Targets for such cross-topical integrated activities so far include Thresholds, tipping points and multiple equilibria in the Earth system; Extreme events and risk assessment; The Earth system in a warmer world; and Data management in support of data service efforts such as US NSF's EarthCube.

Over the next year, the current structure will be replaced by the new one (Fig. 1) and the ongoing current PAGES Working Groups will be mapped onto the new framework.

\section{Call for new working groups}

With the structural changes afoot, and the fact that a significant number of the current working groups are now entering their final phases, it's an opportune time to announce an open call for new working groups to populate the new science structure, particularly the Humans and Environment Themes.

Based on a review of PAGES working groups, the PAGES SSC recently tightened the definition and organizational requirements of PAGES working groups: Working groups should run in ca. 3-year phases with each phase culminating in an intermediary or final major product (e.g. synthesis article, special issue, database, methodology, web-tool). After completing the phase, the working group either sunsets, or proposes a follow-up phase with a new work plan and another major product at the end.

The next deadline for new Working Group proposals is June 2 for consideration at an Executive meeting in June. The guidelines and application form are available at: www.pages-igbp.org/workinggroups/intro. You can also contact Thorsten Kiefer (kiefer@pages.unibe. ch) to discuss your proposal ideas.
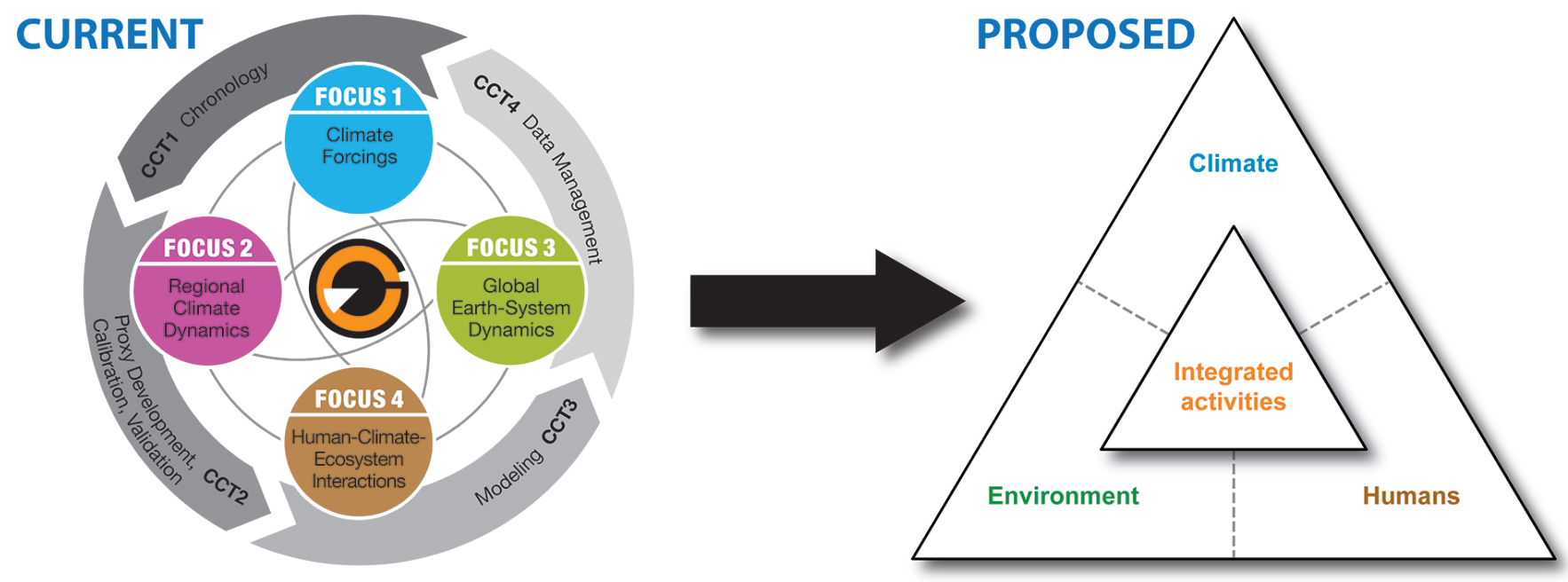

Figure 1: Transition from the current science structure to the new one. The three new topical themes define PAGES' scientific scope. The distinct methodological cross-cutting themes on chronology, proxies and modeling will be abandoned; the boundaries between the distinct foci will be dissolved and a new category of integrative cross-topical activities will be established. Ongoing Working Groups will be re-mapped onto the theme space and new ones will be solicited. 